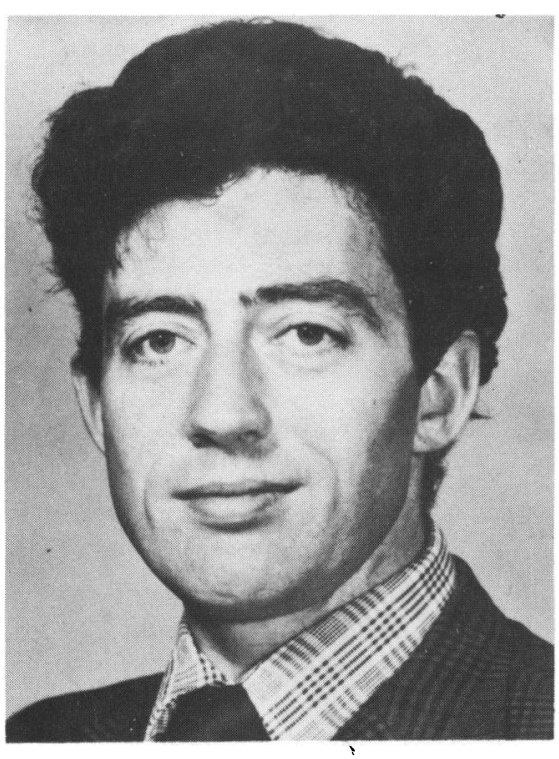

\title{
DEGENERATIVE JOINT DISEASE IN WEIGHT-LIFTERS FACT OR FICTION?
}

B. FITZGERALD, FRCS (G). and G. R. MCLATCHIE, FRCS (G).,

Department of Orthopaedics, Glasgow Royal Infirmary.

\section{ABSTRACT}

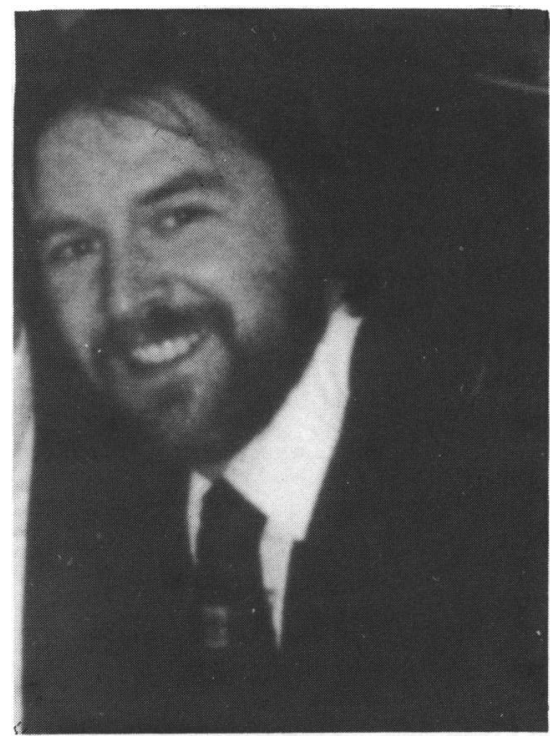

A Clinical and radiological study of upper and lower limb joints was carried out on 25 experienced weight-lifters to $\varrho^{\infty}$ identify the extent of degenerative joint disease (Osteoarthrosis) produced by this sport.

Although significant degenerative changes were found in five lifters $(20 \%)$. This figure is not greater than that found in the general population within the age group studied.

There were more degenerative changes found in Olympic style weight-lifters $(30.7 \%)$ than in power lifters $(8.3 \%) . \stackrel{\varrho}{\Rightarrow}$ The significance of these figures is discussed. The upper limb joints were almost completely free of degenerative $\frac{\rho}{\exists}$ changes.

Key Words

Weight lifting. Degenerative joint disease.

\section{INTRODUCTION}

Degenerative joint disease (osteoarthrosis) is commonly regarded as a "wear and tear" phenomenon. It is associated with abnormal stress on the joint and with the process of ageing. It is rare for a person in the sixth decade to escape some degree of degenerative change in the weight-bearing joints and changes are not uncommon from the third decade onwards. (Sokoloff 1969, Lawrence Bremner \& Bier, 1966).

Many reports have described degenerative joint changes in athletes, the affected joints. varying with the sport. Footballers show degenerative changes in the ankles, knees and symphysis pubis (McMurray, 1950, Odekerken, 1973, Adams and Chandler, 1953). Tennis players and throwers have elbow changes (Priest, Jones et al, 1977). (Woods, Tullos and King, 1973) and even ballet dancers show ankle degeneration (Brodelius, 1961).
Studies have demonstrated degenerative changes in the lumbar spine in weight-lifters and strength athletes (Kotani et al, 1970, Aggrawal et al, 1979) but we can find no reports of the long term effects of weight-lifting 9 on other joints. In view of the increasing use of heavy $\frac{D}{2}$ weight training in the fitness programmes of many?. athletes we felt it pertinent to try to identify the effects $N_{0}$ of long term weight-lifting on the major limb joints.

This paper reports the results of a study on $25 \mathrm{~W}$ experienced weight-lifters. We have looked for degenerative changes not only in the so-called weight-bearing joints of the lower limb but also in the upper limb joints $\Phi_{\mathscr{D}}$ which in this group of athletes are subjected to ? unusually high stress.

\section{CLINICAL MATERIAL}

Twenty-five weight-lifters were included in the study. We accepted only those who had been participating in 
the sport at a high standard for six years or more. Many were of National or International standard. There were thirteen who practised mainly the Olympic style lifts and twelve who were mainly Power lifters, (Olympic weight-lifters compete in the Snatch and Clean and Jerk lifts. Power lifters compete in the Bench Press, Squat and Dead lifts).

The age range was twenty-four to forty-nine years (mean 35.3 years). The number of years practising weight-lifting ranged from six to thirty-two years (mean 17 years). The body weights of the group ranged from $51 \mathrm{~kg}$ to $127 \mathrm{~kg}$ (mean $83 \mathrm{~kg}$ ).

\section{METHOD OF STUDY}

A detailed history was taken in each case to identify any factors predisposing to degeneration such as occupation, other sports or previous injuries and the use of anabolic steroids and other drugs was recorded. In many cases we noted total training poundages used per week to assess roughly the cumulative stress on the joints.

Each participant was examined clinically and radiologically.

\section{Clinical Examination}

The range of motion of the shoulders, elbows, wrists, hips and knees was measured according to the method of the American Academy of Orthopaedic Surgeons (Joint Motion - Method of Measuring and Recording, 1965). In addition the presence of crepitus, pain or deformity of the joints was noted where possible.

\section{Radiological Examination}

In order to limit the radiation exposure single views in the antero-posterior plane only were taken of the acromio-clavicular joints, shoulders, knees and hips. Lateral and antero-posterior views were taken of wrist and elbow and in addition skyline views of the patellae were carried out.

We used the Radiological Gradings of Kellgren and Lawrence (1957) in our assessment of the joints. They divided $X$-ray changes into five grades:

\section{Grade}

0 - indicated definite absence of $X$-ray changes

1 - doubtful

2 - arthrosis definitely present but of minimal severity

3 - moderately severe

4 - the most severe changes.

The radiological features considered to be evidence of osteoarthrosis were joint space narrowing, subchondral sclerosis, marginal osteophytes, peri-articular ossicles and cysts.

\section{RESULTS}

\section{History}

There was no apparent correlation between occupation and osteoarthrosis in this group. Two lifters gave a history of injury sustained during other sports. One had a knee injury caused by football and the other had sustained an acromio-clavicular dislocation at rugby. Both of these joints showed Grade 3 osteoarthrosis.

\section{Clinical Examination}

All participants had well developed musculature, particularly of the shoulders and upper limbs. Three had a varus deformity at the knees, two of $2 \mathrm{cms}$ and one of $3 \mathrm{cms}$ intercondylar distance. One subject had a valgus knee deformity with $3 \mathrm{cms}$ inter-malleolar distance. Only one of the cases with varus deformity had significant degenerative changes. There were no other deformities noted. Crepitus was elicited bilaterally in the patellofemoral joints in twelve patients. In none of these was there associated pain at the time of examination. However, retropatellar aching was said to be common following training.

\section{Joint Mobility}

Joint mobility is shown in Table 1. The range of motion in the shoulders was consistently greater but all other joints were similar in range apart from the hips, where extension and abduction were diminished.

\section{Radiological Assessment}

The Gradings for osteoarthrosis in the upper limbs are shown in Table II and in the lower limbs in Table III.

The only significant abnormality in the upper limbs was Grade 3 osteoarthrosis in one acromio-clavicular joint.

In the lower limbs degenerative changes were more common. However, only three knees (6\%) had Grade 3 (Moderate) changes and there were no cases of severe degeneration (Grade 4).

No degenerative changes greater than Grade 2 were identified in those who practised mainly Power lifting. The most severe changes were restricted to the Olympic lifters. The distribution of lifters with significant degenerative changes is shown in Table IV. In the Olympic group the total number of joints with Grade 2 or 3 changes was twelve, whereas in the Power lifters such changes affected two joints only.

\section{DISCUSSION}

Degenerative joint disease is not uncommon in athletes (McMurray, 1950, Brodelius 1961, Odekerken 1973, Priest et al, 1977) and is assumed to be due to the exces- 
TABLE I

Comparison between the mean range of motion found in this group and that of the American Academy of Orthopaedic Surgeons (A.A.O.A.) for the general population.

\begin{tabular}{|c|c|c|}
\hline JOINT & $\begin{array}{l}\text { Mean range of } \\
\text { movement in } \\
\text { this study }\end{array}$ & $\begin{array}{l}\text { Mean range of } \\
\text { movement in } \\
\text { A.A.O.S. study }\end{array}$ \\
\hline \multicolumn{3}{|l|}{ SHOULDER: } \\
\hline $\begin{array}{l}\text { Forward flexion } \\
\text { Backward extension }\end{array}$ & $\begin{array}{r}186^{\circ} \\
62^{\circ}\end{array}$ & $\begin{array}{r}158^{\circ} \\
53^{\circ}\end{array}$ \\
\hline Internal rotation & $77^{\circ}$ & $70^{\circ}$ \\
\hline External rotation & $97^{\circ}$ & $90^{\circ}$ \\
\hline Neutral abduction & $179^{\circ}$ & $170^{\circ}$ \\
\hline \multicolumn{3}{|l|}{ ELBOW: } \\
\hline Flexion & $147^{\circ}$ & $146^{\circ}$ \\
\hline Hyperextension & $3^{\circ}$ & $0^{\circ}$ \\
\hline \multicolumn{3}{|l|}{ WRIST: } \\
\hline Flexion & $81^{\circ}$ & $73^{\circ}$ \\
\hline Extension & $84^{\circ}$ & $71^{\circ}$ \\
\hline Radial dev. & $23^{\circ}$ & $19^{\circ}$ \\
\hline Ulnar dev. & $34^{\circ}$ & $33^{\circ}$ \\
\hline \multicolumn{3}{|l|}{ FOREARM: } \\
\hline Pronation & $73^{\circ}$ & $71^{\circ}$ \\
\hline Supination & $94^{\circ}$ & $84^{\circ}$ \\
\hline \multicolumn{3}{|l|}{ HIPS: } \\
\hline Flexion & $127^{\circ}$ & $113^{\circ}$ \\
\hline Extension & $9^{\circ}$ & $28^{\circ}$ \\
\hline Abduction & $40^{\circ}$ & $48^{\circ}$ \\
\hline Adduction & $22^{\circ}$ & $31^{\circ}$ \\
\hline Internal rotation & $40^{\circ}$ & $45^{\circ}$ \\
\hline External rotation & $46^{\circ}$ & $45^{\circ}$ \\
\hline \multicolumn{3}{|l|}{ KNEES: } \\
\hline Flexion & $137^{\circ}$ & $134^{\circ}$ \\
\hline Hyperextension & $8^{\circ}$ & $10^{\circ}$ \\
\hline
\end{tabular}

\section{TABLE II}

Radiological assessment of the upper limb. Osteoarthrosis (O.A.) Gradings in two hundred joints. (25 subjects)

\section{O.A. GRADINGS}

$\begin{array}{llllll}\text { JOINT } & 0 & 1 & 2 & 3 & 4 \\ \text { Wrist } & 48 & 2 & 0 & 0 & 0 \\ \text { Elbow } & 42 & 8 & 0 & 0 & 0 \\ \text { Shoulder } & 50 & 0 & 0 & 0 & 0 \\ \text { Acromio-clavicular } & 49 & 0 & 0 & 1 & 0\end{array}$

TABLE III

Radiological Assessment of the Lower Limb. Osteoarthrosis (O.A.) Grading in one hundred and fifty joints.

\section{O.A. GRADING}

$\begin{array}{lrrrrr}\text { JOINT } & 0 & 1 & 2 & 3 & 4 \\ \text { Hip } & 43 & 7 & 0 & 0 & 0 \\ \text { Knee } & 34 & 10 & 3 & 3 & 0 \\ \text { Patello-femoral } & 42 & 1 & 5 & 2 & 0\end{array}$

\section{TABLE IV}

Significant degenerative changes in each group.

\begin{tabular}{lllll} 
& \multicolumn{5}{c}{ Grade 2 or 3 Osteoarthrosis } \\
& No. & $\begin{array}{l}\text { Number of } \\
\text { subjects }\end{array}$ & $\%$ & $\begin{array}{l}\text { Number } \\
\text { of joints }\end{array}$ \\
Olympic lifters & 13 & 4 & $31 \%$ & 12 \\
Power lifters & 12 & 1 & $8 \%$ & 2
\end{tabular}

sive wear and tear associated with sports. The group weo studied are competitive weight-lifters who handle several. tons in the course of an intensive training session. The cumulative stress on their joints is therefore considerable and might be expected to cause marked degenerative changes after a number of years training. However, ourô findings do not support this assumption.

The upper limbs in weight-lifters are required to $\exists$ support loads in excess of body-weight during lifts. We? found that only one lifter had significant degenerative? change (Grade 3) in an upper limb joint, (the righto acromio-clavicular joint) which had been injured during? rugby. Two wrists (4\% of the total number of wrists:studied) and eight elbows (16\%) had changes of doubtful? significance (Grade 1). Reilly, (1978) has suggested that wrist deterioration may occur due to hyperextension. Three lifters only complained of symptoms duringo hyperextension of the wrist, but $X$-rays in these cases were normal.

The mean range of motion in the elbows and wrists $\stackrel{N}{\%}$ was similar to the values given by the American $N$ Academy of Orthopaedic Surgeons (1965). There was N however an exceptional range of shoulder mobility especially among the Olympic lifters, perhaps due to the enforced stretching with this style of lifting. No-one had restriction of movement caused by muscle $\stackrel{\oplus}{\oplus}$ hypertrophy, "muscle bound".

In the lower limb the knees had the most severe changes. The hips were almost completely spared. Only $\underset{\mathbb{Q}}{ }$ seven hips (14\%) had doubtful evidence of degenerative change (Grade 1). All other hips were normal. 
In the femoro-tibial articulation of the knees there were ten Grade 1 changes $(20 \%)$, three Grade $2(6 \%)$, and three Grade 3 changes (6\%), while in the patellofemoral joints there were five Grade $2(10 \%)$ and two Grade 3 changes (4\%) with only one Grade 1 change.

The Grade 3 changes in the femoro-tibial articulation were found bilaterally in one of the oldest subjects and in one other lifter with a history of injury to the right knee and subsequent surgical intervention. The latter is at present a National Olympic Champion!

The patello-femoral joint in the deep squat position may be loaded to 6-7 times body weight (Reilly 1978, Sokoloff 1969). The addition of a load of several hundred pounds during a lift will increase this considerably. However, while almost $50 \%$ of lifters complained of patello-femoral pain and crepitus only $14 \%$ had significant degenerative changes.

The range of motion in the knees was normal. In the hips, extension and abduction was somewhat less than in the American Academy Survey. This may be due to the preponderence of hip flexion movements utilised by the group.

Osteoarthrosis of Grade 2 to 4 in at least one joint in males of age 35-44 years has been found in $38.3 \%$ of the population. (Lawrence et al 1966). In this study only five weight-lifters $(20 \%)$ exhibited degenerative joint changes of Grade 2 or 3, i.e. only half the number found in a sample of the general population.

We realise that this study examines a small and select group but it is nevertheless apparent that long term weight lifting does not produce inevitable joint degeneration. We suspect that in a normal joint, intermittent loading even to a severe degree, does not of itself cause articular degeneration. There may even be some beneficial effect on cartilage nutrition from the compressive pumping action (Radin and Paul, 1972). However, a joint previously injured is likely to be more vulnerable to severe loading and may deteriorate.

We found the most severe degenerative changes within the group of Olympic weight-lifters. The numbers are small and their significance cannot be stated accurately. It is possible however that this dynamic form of weight-lifting with more frequent loss of control of the weight produces greater and more abnormal stresses than the more controlled and less extreme movements of Power lifting.

The use of Anabolic steroids in competitive weightlifters and field athletes is known to be common, and many side effects have been recognised. Twelve subjects (48\%) admitted using anabolic steroids on a regular basis. We found no correlation between degenerative joint disease and the use of anabolic steroids in this small group.

\section{CONCLUSIONS}

Our findings in this study suggest that degenerative joint disease is not an inevitable consequence of long term weight-lifting. However, a previously injured joint is more vulnerable to heavy loading.

\section{REFERENCES}

Adams, R. J., and Chandler, F. A., 1953. "Osteitis Pubis of Traumatic Aetiology." Journal of Bone and Joint Surgery. 35A: 685-696.

Aggrawal, N. D., Kaur, R., Kumar, S., and Mathur, D. N., 1979. "A Study of the Changes in the Spine in Weight-lifters and Other Athletes." British Journal of Sports Medicine, 13: 58-61.

American Academy of Orthopaedic Surgeons 1965. In Joint Motion. Method of Measuring and Recording. Edinburgh and London. E. and S. Livingstone.

Brodelius, A., 1961. "Osteoarthrosis of the Talar Joints in Footballers and Ballet Dancers." Acta Orthopaedica Scandinavica 30: 309-314.

Kellgren, J. H., and Lawrence, J. S., 1957. "Radiological Assessment of Osteoarthrosis." Annals of the Rheumatic Diseases. 16: 494-502.

Kotani, P. T., Ichikawa, N., Wakabashi, W., Yoshii, T., and Koshimune, M., 1970. "Studies of Spondylolysis Found Among Weight-lifters." British Journal of Sports Medicine, 6: 4-8.

Lawrence, J. S., Bremner, J. M., and Bier, F., 1966. “Osteoarthrosis. Prevalence in the Population and Relationship Between Symptoms and X-ray Changes." Annals of the Rheumatic Diseases. 25: 1-23. 
McMurray, T. P., 1950. “Footballer's Ankle." Journal of Bone and Joint Surgery. 32B: 68-69.

Odekerken, J. C., Chantraine, A., and Bernard, A., 1973. "Arthrose et deviation axiale du genou chez les anciens? joueurs de football." Journal Belge de Rheumatologie et de Medecine Physique. 28: 74-85.

Priest, J. D., Jones, H. H., Tichenor, C. J. C., and Nagel, D. A., 1977. "Arm and Elbow Changes in Expert Tennis Plaỷers." Minnesota Medicine 60: 399-404.

Radin, E. L., and Paul, I. L., 1972. "A Consolidated Concept of Joint Lubrication." Journal of Bone and Joint Surgery, 54A: 607-616.

Woods, G. W., Tullos, H. S., and King, J. W., 1973. "The Throwing Arm: Elbow Joint Injuries," Journal of Sports Medicine, and Physical Fitness 1: 43-48.

Sokoloff, L., 1969. "In the Biology of Degenerative Joint Disease." Chapter 7. The University of Chicago Press.". Chicago and London. 